\title{
SIMULATION OF THE VOTING PROCESS AT POLLING STATIONS
}

\author{
Vadim O. Evseev ${ }^{1, a}$, Tatiana V. Skryl|,b,* \\ 1117997, Stremyannyi lane, 28-340, Moscow, Russia \\ 2127566, Rimskogo-Korsakova str. 10-193, Moscow, Russia \\ amanrus@mail.ru, bt_skryl@mail.ru \\ ${ }^{*}$ Corresponding author
}

\begin{abstract}
Keywords: Elections, Simulation model, Distribution of votes, Political experiment, Political modeling
\end{abstract}

\begin{abstract}
The article considers the factors that have a certain influence on the voting process. The goal of the research is to develop an algorithm and model for the construction of political space and variant behavior of voters in the process of political elections. Methods: the research is based on the system analysis of the voting process, the theory of probability and distribution laws, and the method of political modeling. Result: a multi-factor simulation model of voting at the polling station with interface graphical information is constructed. In summary, the authors concluded it is possible to build complex models for any region based on the proposed model. The model allows students and researchers to carry out political experiments seeking the advantages for the chosen political party.
\end{abstract}

\section{Introduction}

Economic, social, technical, innovative development of the state, the development of civil society is inextricably linked with the conscious involvement of citizens in the process of political and economic relations through their participation in elections, protests and other political campaigns and actions. Political preferences of voters and their political behavior depend on their role in the system of hierarchical relations, social status, financial situation, as well as the state of the surrounding socio-economic situation, the level of social tension.

One of the elements of the formation and functioning of the political system of the state is political elections[1,2]. Their subject is society in the person of its capable citizens, and the object is political and state power. Political elections are a way of forming the bodies of state power and public administration by expressing the political will of citizens in accordance with the current electoral system. By means of elections, Central and local representative bodies of state power are formed, candidates for elected positions (from the President or the head of government) are determined. Elections may be presidential; parliamentary; municipal; regular; extraordinary; additional.

In political science literature, we can find the statement that elections are nothing more than a kind of political ritual, allegedly not having a decisive influence on the political processes of the state. They only create the appearance of citizens ' involvement in political decision-making, as voters vote for candidates who are offered to them by political parties. Nevertheless, a democratic system of elections is an important component of the mechanism of state power[3].

Election results are always probabilistic, because the voting results are subject to certain distribution laws[4]. With the development of political sociology, sociology of financial behavior, economic sociology, with the development of the theory of small groups, the theory of rational choice, etc., there was initial information and methodological basis for the construction of simulation models of political choice[5]. Such models allow, on the one hand, to construct a political space and political interaction to obtain the expected political result, on the other hand, by modeling methods it is possible to predict the development of political processes and obtain the probabilistic characteristics of the planned political events. 


\section{Methodology}

Computer business games refers to active teaching methods, which imply the presence of a mathematical or formalized model, simulating various aspects of the behavior of the object under study [6]. The models can reflect both the activity of economic objects and trajectories of movement, strategic decision-making, i.e. any objects and processes, the essential content and target aspirations of which can be formalized and translated into algorithms of their behavior $[7,8]$.

The modeling method is the basis for the development of computer business games, which are widespread in the West[9]. Business games are an integral part of University programs at the faculties of political science and economics.

The developed computer model should meet the principles of consistency and criterion, i.e. a mathematical or formalized model, which is the basis of the business game, is evaluated by the criterion of internal consistency and the criterion of external likelihood. The criteria of consistency and likelihood allow us to build a model that reflects the typical realities associated with typical internal and external reactions of the simulated object.

An important aspect of the model used in the business game is its interactive interface, which immediately and clearly allows you to determine, evaluate and show the effectiveness of management decisions. In a computer business game, the "method of trial and error" is fully implemented, when the playing party immediately sees the price of damage from erroneous decisions.

One of the most important aspects of a business computer game is the possibility of conducting experiments on a computer model of the object of research, the collection of experimental statistical information and the processing of this information in order to identify new dependencies.

Game concept. Consider the concept of a computer business game designed to assess the impact of a number of external factors on the results of voting for political parties in polling stations.

Working with the model consists of several stages.

The first stage: the design of the territories. At this stage, the players create their own settlements, determine their location in the coordinate system (X, Y) and set the population that lives in these settlements (see figure 1)[10].

The second stage: the design of the electoral space. At this stage, playing in the coordinate system $(\mathrm{X}, \mathrm{Y})$ themselves distribute the location and number of polling stations (see figure 1)[11].
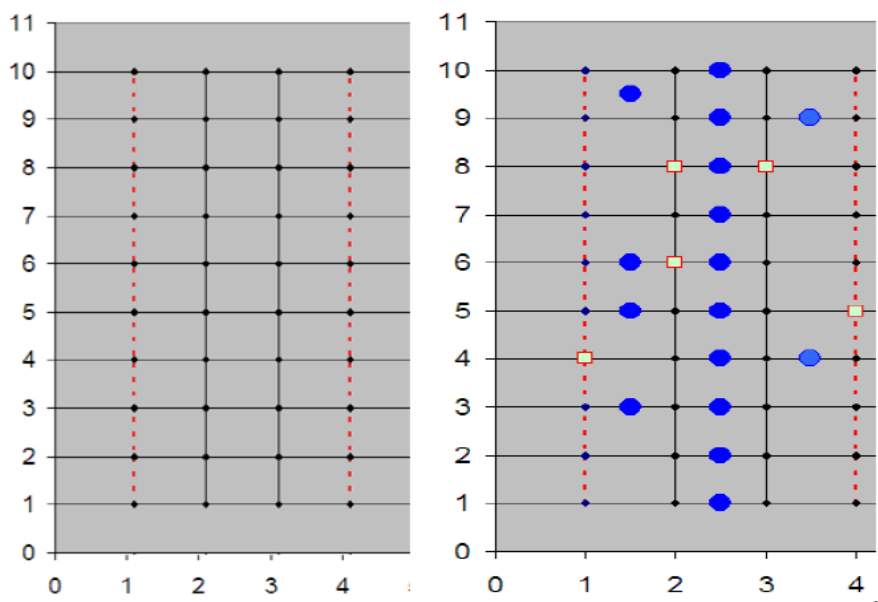

Fig. 1. Settlements (blue) and polling stations (red) in the coordinate system (here is five polling stations)

The third stage: for the residents of each locality is given the following information:

1) probability of voting for one of the parties;

2) indicator of the unity of the electorate, which supports its party;

3 ) indicator of the level of relevance of the electoral program of the parties for the electorate.

The Player sets:

1) location of polling stations; 
2) certain characteristics of the electorate;

3) the coefficient of complication of the elections by polling stations: holidays, weather conditions;

4) voting time of the electorate - it can create preferred situations for a particular party. The results of voting are immediately displayed in the form of graphical information.

The goal of the game is a clear consolidation of logical links between a certain set of concepts: "electorate - party affiliation - party cohesion - the relevance of the election party program"; "distribution of settlements - the population in them - the distribution of polling stations"; "voting results - complicating natural and social factors - the cohesion of the electorate"[12].

The model is based on the system of calculations between the indicators of settlements and the indicators of polling stations, as well as the system of probabilities of occurrence of the events indicated in the model. The game model includes a fairly complex algorithm of calculations, on the other hand, the model demonstrates the possibility of creating a real model of political elections. The initial information for the real model is collected by the methods of political sociology.

\section{Results}

\subsection{Input Parameters of the Model}

The created social and political infrastructure of the settlement with its population and with its party political preferences and with its system of party assessments. The population, on election day, expresses its political will.

Where:

$$
\mathrm{Yt}=\mathrm{F}(\mathrm{Yt}-1 ; \mathrm{X} 1 \mathrm{t} ; \mathrm{X} 2 \mathrm{t} ; \mathrm{X} 3 \mathrm{t} ; \mathrm{X} 4 \mathrm{t} ; \mathrm{X} 5 \mathrm{t} ; \mathrm{X} 6 \mathrm{t} ; \mathrm{X} 7 \mathrm{t} ; \mathrm{X} 8 \mathrm{t})
$$

External / exogenous factors in the model are:

$\mathrm{X} 1 \mathrm{t}$ - defined coordinate system of settlements;

$\mathrm{X} 2 \mathrm{t}$ - defined coordinate system of polling stations;

$\mathrm{X} 3 \mathrm{t}$-population in settlements;

X4t-three political parties: Blue, Purple, Yellow;

X5t-factors complicating the voting process: weather, social;

$\mathrm{X} 6 \mathrm{t}$ - the probability of selecting the electorate of one of the parties;

$\mathrm{X} 7 \mathrm{t}$ - the level of party unity of the electorate of his party;

$\mathrm{X} 8 \mathrm{t}$-significance of the electoral program of political parties for the electorate;

\subsection{Output information}

Y1t - distribution of votes by polling stations;

Y2t-the number of votes cast for the parties by precincts and in general;

The interface information about the possible States of the output parameters can be presented in the form of various graphs. The graphs show the electoral activity of the population, as well as the number of voters.

By implementing a model, students or researchers can immediately get an idea of what political parties can win depending on the value of the input factors.

The graphs can be given options for a model political experiment associated with the results of voting with different characteristics of voters who are members of one of the parties represented. In each case, the impact of such characteristics as "unity of party ranks" and "relevance of the content of the election party programs", which are offered to voters, on the voting results can be evaluated.

\section{Summary}

Leading political parties and political forces before elections always offer voters a "model of the future", the socio-economic indicators and characteristics of which should convince voters to vote for 
its implementation, and therefore for the political party that proposed this model. Political sociology makes it possible to find out the system of voters 'responses to political parties' policy documents and to identify electoral preferences, thus forming the information basis for the model. Political modeling makes it possible to study the process of political voting, to identify hidden mechanisms and contradictions that affect the electoral process, helps to obtain complex cause-and-effect relationships based on initial assumptions. In our case, the model is based on the principles of an independent division of mathematics - computational mathematics, which allows more accurately describe the logical relationship of political processes. It is possible to build a model of the voting process at polling stations for any region if there is a request.

\section{References}

[1] Naylor T.H., Computer Simulation Experiments with Models of Economic Systems. NY, J. Wiley, p. 502,1971

[2] Manheim Jarol B., Empirical Political Analysis - Quantitative and Qualitative Research Methods. 7th edition. Pearson Longman, p. 445, 2008.

[3] Dementiev, Victor E., Ustyuzhanina, Elena V., The Problem of Power: Institutional Approach. Journal Of Institutional Studies, Volume: 8, Issue 3, Pp. 91-101, 2016.

[4] Keane John, Democracy and Civil Society. The University of Westminster, W1T 3UW, London, UK, 1988.

[5] Lave Ch., March J.Q. An Introduction to Models in Social Sciences. N.Y.: Harper and Row. p. 3, 1978.

[6] Samuel P. Huntington, The Crisis of Democracy Trilateral Commission Report, p. 113, 2004.

[7] Bellucci, P., Costa Lobo, M., Lewis-Beck, M.S. Economic Crisis and Elections: The European Periphery. Electoral Studies, 31 (3), pp. 469-471, 2012.

[8] Lobo, M.C., Ferreira da Silva, F., Prime Ministers in the Age of Austerity: An Increase in the Personalisation of Voting Behaviour. West European Politics, Volume 41, Issue 5, Pp. 1146-1165

[9] Skryl, Tatiana V., Osipov, Vladimir S., Evseev, Vacm O. The interaction model of business and state as a factor in human resource management. Proceedings of the Second International Conference on Economic and Business Management, Volume: 33, pp. 862-868, 2018.

[10]The system of analysis of voting results at the meetings of the state Duma [Electronic resource]. URL: http://vote.duma.gov Oh?EN/vote/9061

[11]Public opinion Foundation (POM) [Electronic resource]. URL: http://fom.ru

[12] Evseev V. O. Competitiveness in the new socio-economic formation (Economic model of the new vector of development of society). Riga: Palmarium Academic Publishing, 2016. 